EGU2020-18764

https://doi.org/10.5194/egusphere-egu2020-18764

EGU General Assembly 2020

(c) Author(s) 2020. This work is distributed under

the Creative Commons Attribution 4.0 License.

\title{
The water-food-energy-land nexus: Hotspots and scenario- dependency of competition for water between energy, food and nature
}

Lotte de $\operatorname{Vos}^{1,2}$, Hester Biemans ${ }^{2}$, Jonathan Doelman ${ }^{1}$, and Elke Stehfest ${ }^{1}$

${ }^{1}$ PBL Netherlands Environmental Assessment Agency, The Hague, The Netherlands

${ }^{2}$ Wageningen Environmental Research, Wageningen University \& Research, Wageningen, The Netherlands

Freshwater is a shared resource needed both for food and energy production, and to sustain ecosystems worldwide. Freshwater ecosystems are already experiencing biodiversity declines that are higher than in most terrestrial systems. With climate change and an expected increase in global population and income, the trade-offs between societal demand and nature become even more stringent. Insight in how these developments might impact future water use helps to identify strategies to ensure a healthy environment while still meeting global water demands.

This study evaluates competition for water within the food-water-energy nexus, while explicitly accounting for the amount of water required by nature. It does so by implementation of Environmental Flow Requirements (EFRs), which are in this case defined as the quantity and timing of water flows required to sustain freshwater and estuarine ecosystems. Simulations are performed with the integrated assessment model framework IMAGE, which includes the global vegetation and hydrology model LPJmL. This framework combines regional agro-economic, energy and climate policy modelling with land-use, dynamic vegetation and hydrological modelling.

Different pathways of socio-economic developments (Shared Socio-economic Pathways (SSPs)) are evaluated up until the year 2100 , including a climate change mitigation scenario aiming for the long-term mitigation target of $2^{\circ} \mathrm{C}$. Earlier studies for SSP-1, SSP-2 and SSP-3 have already shown that while global water withdrawals are expected to increase for all cases, the demands for SSP-3 are generally higher than the demands for SSP-1. This study adds to this by showing how water demands affect environmental flows, or vice versa. The results present an overview of hotspots where future water demand for food, energy and nature might still compete, and where the effects are ameliorated if the world will develop towards a more sustainable path. Additionally, the results present how irrigation efficiency improvements and climate change mitigation measures can help alleviate the pressure in the food-water-energy nexus, although the latter depends on the choice of mitigation pathway.

How to cite: de Vos, L., Biemans, H., Doelman, J., and Stehfest, E.: The water-food-energy-land 
nexus: Hotspots and scenario-dependency of competition for water between energy, food and nature, EGU General Assembly 2020, Online, 4-8 May 2020, EGU2020-18764,

https://doi.org/10.5194/egusphere-egu2020-18764, 2020 